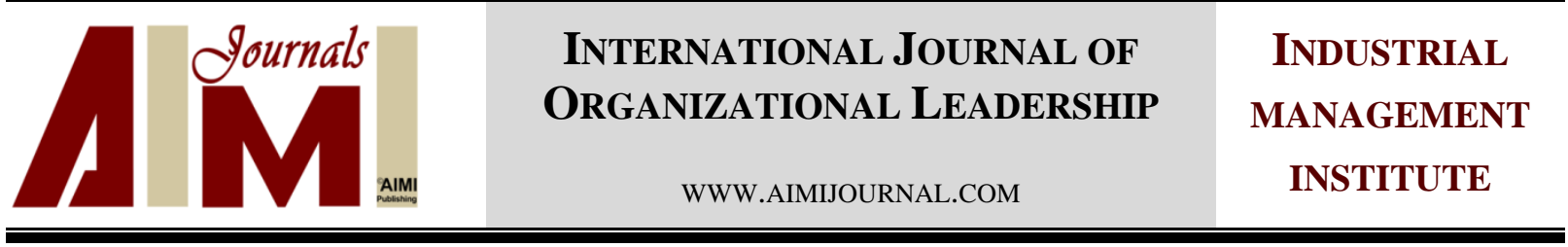

\title{
Studying the relationship between organizational intelligence and organizational agility of employees of Payame Noor University of Sari
}

\author{
Eshaq Rasouli ${ }^{1}$, Shahla Soodi ${ }^{2 *}$, Zahra Jafarzadeh ${ }^{3}$ \\ ${ }^{1}$ Assistant Professor, Ardabil Branch, Islamic Azad University, Ardabil, Iran \\ ${ }^{2} \mathrm{PhD}$ Student, Faculty of Management, Ardebil Branch, Islamic Azad University, Ardabil, Iran \\ ${ }^{3}$ MA Graduate of MBA, Nooretouba Institute of Higher Education
}

\begin{abstract}
Keywords:

Organizational Agility, Payame-Noor University of Sari, Organizational Intelligence

Received

16 June 2016

Received in revised form 16 August 2016

Accepted

17 September 2016

Correspondence:

sh_soodi@yahoo.com

This study aimed to investigate the relationship between organizational intelligence and organizational agility of employees of Payame Noor University of Sari. This paper was an applied research adopting a descriptive-correlational method and survey design. The statistical population of this study consisted of all 60 employees of Payame Noor University of Sari which are working since 2015. Due to the limited size of the target population, the total population was considered as the sample. Two questionnaires were used in order to collect data and information. Karl Albrecht's standard questionnaire with 49 items with five-point Likert scales which included seven dimensions or components of organizational intelligence namely strategic vision, shared fate, appetite for change, alignment and congruence, spirit, knowledge deployment, and performance pressure. Cronbach's alpha was used as an estimate of reliability. The second questionnaire contains 16 items that assess specific organizational agility. To analyze the data, descriptive statistics, inferential statistics, and Pearson's product moment correlation coefficient were used. The results of the study showed that there was a linear relationship between two variables of organizational intelligence and organizational agility of employees in Payame Noor University of Sari.
\end{abstract}

(C)AIMI Journals

In all business jobs all around the world, we are witness to rapid growth and development along with new requirements. Technological advances, the need for constant updating of information and knowledge, enhancement of original information sharing among various 
parties lead to a change in labor force quality in each of these sectors (Potas, Ercetin, \& Kocak, 2010). Intelligence is one of the new concepts to help the organizations and management to reach an appropriate level which has attracted a great deal of interest recently. Due to the novelty of this issue, the existing literature on theoretical contribution and modeling of organizational intelligence is rather weak. Knowledge management is not considered as a new process. In the past few decades, more than 4000 studies focused on only the written media and more than a hundred newspapers used the model of knowledge management (Girard \& McIntyre, 2010). One of the biggest challenges that we encounter these days is how to form new generation of intelligent organizations. Intelligence in organizations is considered as determining factor and proper use of it can lead to a significant increase in the productivity of the organization. If it is neglected, it will remove any other organization from the competition and the survival process (Kohansal, 2009). So, organizational intelligence in today's complex organizations is a combination of two active human intelligence and artificial intelligence. Therefore, the organization's managers have no choice to take advantages of these two dynamic trends for increasing the efficiency of their organizations. Albrecht (2002) referred to the organizational intelligence as the capacity of an organization to apply its all employees' thinking power and then direct them. Therefore, thinking power toward the mission of the organization is defined as intelligence. He believed when intelligent people are employed in an organization, a group generally tends to be stupid and therefore the organizations are damaged by themselves rather than by their competitors. Lack of administrative skills, office wars, and political campaigns at all levels, organizing disorder, meaningless rules and procedures, and all other consequences are factors that prevent a business from using all brain powers just for money deals. People may be highly intelligent and capable to do great things, but the cumulative force of their brain activity cause to do great work. Albrecht (2002) believed that organizational intelligence has seven dimensions. Weber (1996) believed that an organization's ability to shape the environment in accordance with its objectives and competences is called organizational intelligence. According to the advances in science and technology and the emergence of new needs and challenges, organizations are far more difficult to manage them. The concept of intelligence becomes more important when we admit it as a great source of creativity for smart human. Intelligent mechanical device has a significant role on the performance process of organizations. In such changing learning conditions, organizations are forced to remain competitive in order to adapt themselves with the changes of organizational agility as a new paradigm and response to them. However, in today's complex organizations, intelligence is considered as a combination of human intelligence and artificial intelligence. Therefore, the managers should take advantage of it for their organizations' dynamism and efficiency. Agility is an ability to respond and react quickly and successfully to the environmental changes. In the $21^{\text {st }}$ century competition, other organizations or institutions as producers are forced to be agile to compete effectively in dynamic global marketplace (Dolat Modeli, 2008). An agile organization will not lose its uniformity easily by sudden change of events. An agile organization is high-speed, consistent, and powerful and therefore gives rapid response to sudden changes, new market opportunities, and customer requirements. An agile organization can understand and predict the changes in the business environment to make its structure properly (Jafarnejad \& Shahaei, 2007). 
Seyyed Ameri (2009) studied the relationship between organizational intelligence and organization agility. The results showed that there was a significant positive relationship between organizational agility and its components in terms of demographic characteristics expect for field studies. Moreover, there were a significant positive relationship between intelligence and its components and organizational agility in administration. The results of his study showed that there was a significant difference between line and staff units regarding to organizational intelligence. Furthermore, there was a significant difference between line and staff units of Sepah Bank in terms of strategic vision, belief in common destiny, the index of unity and consensus, morale, assessing the knowledge and attitude of managers in relation to the employees' performance. It also indicated that there was a significant difference in both line and staff units based on the desire of the personnel changes. Bagherzadeh and Akbari Dibavar (2010) investigated the relationship between organizational intelligence and organizational agility. The results of his study showed that there was a significant positive correlation between organizational intelligence and organizational agility. Also, there were significant relationships between some dimensions of intelligence including common fate, desire for change, unity and consensus, morale, knowledge application, and performance pressure with organizational agility but he could not find any significant relationship between organizational agility and strategic vision (Khodadadi, Kashef, Seyyed Ameri, \& Aalami Kashki, 2013). Lefter, Prejmerean, and Vasilache (2008) studied the organizational intelligence of Romanian companies in which human was the main capital. The results showed that only 13 percent of employees in small firms did not recognize this concept. However, the results of data analysis showed that organizational intelligence was in the average or high level. Then, the components of intelligence were identified based on Albrecht's view (2002, 2003). Chakir and Ada (2008) investigated the role of training at the workplaces to develop organizational intelligence in Turkey. The results tended to differ substantially in intelligence before and after the workshop. There was not a significant difference in the efficiency of communication among colleagues.

So, the present study aimed to identify the relationship between organizational intelligence and organizational agility of employees of Payame Noor University of Sari.

\section{Research Hypotheses}

In line with the discussion above, the following research hypotheses were formulated:

$\mathbf{H}_{\mathbf{0 1}}$ : There is a significant positive relationship between organizational intelligence and organizational agility of employees of Payame Noor University of Sari.

$\mathbf{H}_{\mathbf{0 1 a}}$ : There is a significant positive relationship between strategic vision and organizational agility of employees of Payame Noor University of Sari.

$\mathbf{H}_{\mathbf{0 1 b}}$ : There is a significant positive relationship between shared fate and organizational agility of employees of Payame Noor University of Sari.

$\mathbf{H}_{\mathbf{0 1}}$ : There is a significant positive relationship between desire for change and organizational agility of employees of Payame Noor University of Sari.

$\mathbf{H}_{\mathbf{0 1 d}}$ : There is a significant positive relationship between alignment and congruence and organizational agility of employees of Payame Noor University of Sari. 
$\mathbf{H}_{01 \mathrm{e}}$ : There is a significant positive relationship between spirit and organizational agility of employees of Payame Noor University of Sari.

$\mathbf{H}_{\text {01f: }}$ : There is a significant positive relationship between knowledge deployment and organizational agility of employees of Payame Noor University of Sari.

$\mathbf{H}_{\mathbf{0 1}}$ : There is a significant positive relationship between performance pressure and organizational agility of employees of Payame Noor University of Sari

\section{Conceptual Model of Research}

An overview of this study is presented in the conceptual framework given in Figure 1.

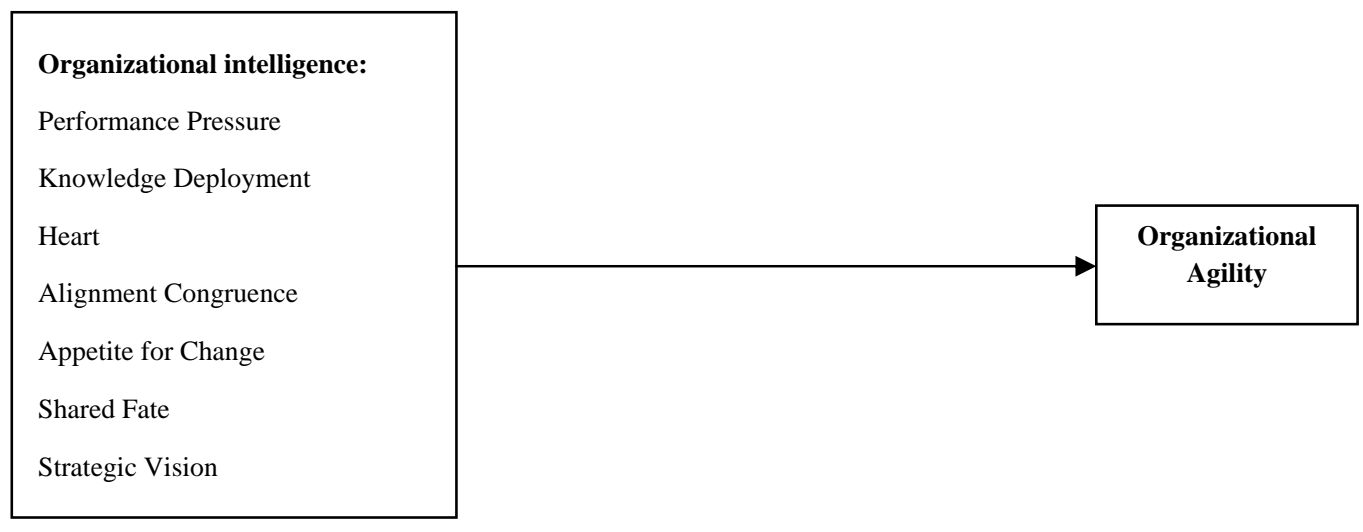

Figure1. Conceptual framework of research

\section{Method}

This paper was an applied research adopting a descriptive-correlational method and survey design. The participants of the study were consisted 60 employees working at Payame-Noor University of Sari who were working since 2015. Due to the limited size of the target population, the total population was considered as the sample of study. Two standard questionnaires were used in this study for collecting initial data including Karl Albrecht's Standard questionnaire of organizational intelligence (2003) and inventory of organizational agility. The first questionnaire consisted of 49 items on 7 components that each rated using a 5point Likert scale (strong agreement to strong disagreement). This questionnaire consisted of seven sub-components that measure strategic insight (2-3-15-17-22-42-48), common fate (4-919-33-36-44-47), desire for change (13-14 -24-28-34-43-45), morale (1-5-6-10-25-37-40), unity and consensus (12-18-20-26-38-39-41), knowledge application (7-21-23-29-30-31-35), and performance pressure (8-11-16-27-32-46-49).

The second questionnaire contained 16 items for measuring organizational in four main components namely competency, accountability, flexibility, and speed. Five-point Likert items were used categorical items including very low, low, medium, high, and very high. Based on the data gathered, the reliability coefficient alphas were calculated through Cronbach's alpha to be 0.96 and 0.87 , respectively. The research hypotheses were tested using both the descriptive statistical as well as the inferential statistical method. In addition, Pearson's product moment correlation coefficient has been utilized for analyzing data. 


\section{Results}

Table 1 presents the descriptive statistics of organizational agility and organizational intelligence with their subscales.

Table 1

Descriptive Statistics Indexes of Organizational Intelligence \& Organizational Agility

\begin{tabular}{lccccc}
\hline Variable & Minimum & Maximum & SD & Mean & Number \\
\hline Organizational Intelligence & 49 & 227 & 32.49 & 178.98 & 60 \\
Strategic Vision & 7 & 33 & 4.83 & 24.80 & 60 \\
Shared Fate & 7 & 33 & 5.19 & 25.18 & 60 \\
Appetite for Change & 7 & 33 & 5.31 & 24.72 & 60 \\
Spirit & 7 & 33 & 5.08 & 25.38 & 60 \\
Alignment Congruence & 7 & 34 & 5.75 & 26.90 & 60 \\
Knowledge Deployment & 7 & 33 & 5.62 & 27.30 & 60 \\
Performance Pressure & 7 & 32 & 4.33 & 24.70 & 60 \\
Organizational Agility & 16 & 80 & 14.10 & 64.97 & 60 \\
\hline
\end{tabular}

Table 1 shows that organizational intelligence and organizational agility mean scores which are 4.06 and 3.65 respectively are higher than the moderate level. Generally, it can be concluded that the organizational intelligence and organizational agility of employees of Payame-Noor University of Sari placed in satisfactory condition. Therefore, the main hypothesis which states there is a significant positive relationship between organizational intelligence and organizational agility of employees of Payame-Noor University of Sari.

Table 2

Results of Pearson Correlation Coefficients for Main and Sub-Hypotheses of the Study Hypotheses

\begin{tabular}{|c|c|c|c|}
\hline $\begin{array}{l}\text { Main Hypothesis (Total perceived } \\
\text { organizational intelligence) }\end{array}$ & 0.79 & $\begin{array}{l}\text { Fourth Sub-Hypothesis (Total perceived } \\
\text { alignment and congruence) }\end{array}$ & 0.77 \\
\hline $\begin{array}{l}\text { First Sub-Hypothesis (Total perceived } \\
\text { strategic vision) }\end{array}$ & 0.75 & $\begin{array}{l}\text { Fifth Sub-Hypothesis (Total perceived } \\
\text { spirit) }\end{array}$ & 0.72 \\
\hline $\begin{array}{l}\text { Second Sub-Hypothesis (Total } \\
\text { perceived shared fate) }\end{array}$ & 0.63 & $\begin{array}{l}\text { Sixth Sub-Hypothesis (Total perceived } \\
\text { knowledge deployment) }\end{array}$ & 0.67 \\
\hline $\begin{array}{l}\text { Third Sub-Hypothesis (Total perceived } \\
\text { desire for change) }\end{array}$ & 0.74 & $\begin{array}{l}\text { Seventh Sub-Hypothesis (Total perceived } \\
\text { performance pressure) }\end{array}$ & 0.66 \\
\hline
\end{tabular}

According to Table 2, the relationship between perceived control and total perceived organizational intelligence was investigated using product-moment correlation coefficient. Preliminary analyses were performed to ensure no violation of the assumptions of normality, linearity, and homoscedasticity. The results showed that there was a strong positive correlation between two variables, organizational intelligence and organizational agility, the significance level was 0.00 which was smaller than 0.05 . With respect to the Pearson Correlation which was calculated about 0.79 that was greater than the critical value of Pearson confidence level $(0.25)$, the main hypothesis was confirmed which stated that there is a significant positive relationship between organizational intelligence and organizational agility of employees of Payame-Noor University of Sari. Furthermore, the results of Pearson correlation showed that there are significant positive relationships between each dimension of organizational intelligence including strategic vision, shared fate, desire for change, alignment and congruence, spirit, 
knowledge deployment, and performance pressure and organizational agility of employees of Payame-Noor University of Sari because the significance level for each sub-hypothesis is less than $0.05(p<0.05)$.

\section{Discussion and Conclusion}

The present study set out to show that there was a significant positive relationship between organizational intelligence and organizational agility of employees of Payame-Noor University of Sari. Furthermore, all components of organizational intelligence including strategic vision, shared fate, desire for change, spirit, alignment and congruence, deployment of knowledge, and pressure performance had significant relationships with organizational agility. To have an agile organization, the employees of that organization should have a desire for change and a common purpose. Through enhancing congruence by aligning and deployment of knowledge, we can improve the performance of organization and therefore provide situations for growth, development, and agility for organization. The results of this study are consistent with previous findings such as Bagherzadeh and Akbari Dibavar (2010), Chakir and Ada (2008), Seyyed Ameri (2009), and Lefter et al. (2008). These conclusions needed further support through follow-up studies that target the issue empirically. Below some suggestions are made for strengthening different dimensions of organizational intelligence. Firstly, the organizations' senior managers need to review and revise the organizational strategies every year to empower their own strategic vision. Secondly, it is recommended to strengthen the sense of shared fate among managers and employees the managers should be willing to cooperate with employees in important issues and programs and share the outcome with them. Besides, it is recommended that the organizations' activities modify and adapt constantly based on environmental changes and organizational transformations to strengthen the managers' desire for change. To increase the spirit of working among the employees, it is recommended that the managers should establish recreational programs, family holidays, and national and religious programs which are suitable for various occasions, employees, and their families to improve the quality of work life of the employees in the organization. Another suggestion is related to the design of an information system for empowering the employees and strengthening congruence and alignment. Other constructive suggestion states that the organizations should set up Internet sites and launch some websites to enable the employees to be aware of the latest changes and studies related to their organizations and jobs. Finally, it is better for managers to give appropriate feedback to their employees’ performances.

\section{References}

Ahmadi, M. (2008). Organization and management (general management) principles (8 ${ }^{\text {th }}$ ed.). Tehran: Cultural Research Publications.

Albrecht, K. (2002). Organizational intelligence and knowledge management the executive perspective. Retrieved, 2006, From. http://www. Karl Albrecht.com.

Albrecht, K. (2003). Organizational intelligence survey preliminary assessment. Provided by Karl Albrecht international. Retrieved, 2006, From. http://www.karl Albrecht.com

Bagherzadeh, M., \& Akbari Dibavar, A. (2010). The relationship between intelligence and organizational agility. Business Management Journal, 2(5), 103-121.

Chakir, R., \& Ada, S. (2008). Can the organizational intelligence be developed in-schools by in service training? World Applid Scienes Journal, 4(1), 24-30.

Dolat Modeli, M. (2008). Strategies for achieving agility in organizations. Web magazine, 72, 67-83. 
Girard, J., \& McIntyre, S. (2010). Knowledge management modeling in public sector organizations: A case study. International Journal of Public Sector Management, 23(1), 71-77.

Jafarnejad, A., \& Shahaei, B. (2007). Introduction to organizational agility and agile manufacturing. Tehran: Mehraban Publication.

Khodadadi, M. R., Kashef, M., Seyed Ameri, M., \& Aalami Kashki, M. (2013). The relationship between the components of organizational intelligence and organizational culture in the general department of exercise of east Azerbayjan. Exercise Management, 5(3), 175-189.

Kohansal, H. (2009). Reliability and validity assessment for the organizational intelligence and its relationship with organizational commitment of staff in Shiraz Telecommunication Company (Unpublished master's thesis). Islamic Azad University, Marvdasht.

Lefter, V., Prejmerean, M., \& Vasilache, S. (2008). The dimension of organizational intelligence in Romanian companies: A human capital perspective. Theoretical \& Applied Economics, 23(12), 39-52.

Potas, N., Ercetin, S. S., \& Kocak, S. (2010). Multi dimensional organizational intelligence measurements for determining the institutional and managerial capacity of girl's technical education institution. African Journal of Business Management, 4(8), 1644-1651.

Seyyed Ameri, M. H. (2009). Determining the relationship between conflict management strategies (interpersonal) and spirit and job satisfaction of sports coaches of department of Physical Education of Urmia. Journal of Research in Sports Sciences, 22, 67-80.

Weber, S. E. (1996). Toward more intelligent organizations. In R. W. Blanning \& D. R. King (Eds.), Organizational intelligence in organizational design, modeling, and control (pp.29-30). Los Alamitos, CA: Information System Series. 